\title{
"Revitalización" sindical y negociación colectiva en Argentina (2003-2011)
}

\section{Clara Marticorena*}

Perfiles Latinoamericanos | Artículo vol. 23 | núm. 46 | 2015

pp. $173-195$

\begin{abstract}
Resumen
A partir del análisis de las características y contenidos de la negociación colectiva en Argentina, este artículo establece una serie de contrapuntos sobre las características del protagonismo sindical en el periodo 2003-2011. A lo largo del trabajo se analizan dimensiones comúnmente utilizadas como indicadores de "revitalización" sindical: la incidencia de la negociación colectiva, su cobertura, y los niveles de negociación. Se indaga además en los contenidos salariales y no salariales en convenios colectivos de trabajo y actas de acuerdo. Ello permite problematizar el protagonismo y la acción sindical durante el periodo estudiado y plantear distintas interrogantes sobre la relación entre la orientación y las estrategias sindicales y los contenidos de la negociación colectiva.
\end{abstract}

\begin{abstract}
This paper discusses trade union's revitalization in Argentina during 2003-2011 from the analysis of collective bargaining's characteristics and contents. We study dimensions uses as union revitalization's indicators like number of collective agreements and collective bargaining structure. Also, we investigate collective agreement's contents. The analysis allows us rethink trade unions revitalization's characteristics in Argentina and develop a series of questions on relation between union's strategies and collective agreement's contents.
\end{abstract}

Palabras clave: negociación colectiva, sindicatos, revitalización, flexibilización laboral, Argentina, kirchnerismo.

Keywords: collective bargaining, trade unions, revitalization, labour flexibility, Argentina, kirchnerismo.

* Licenciada en Sociología, magister en Ciencias Sociales del Trabajo y doctora en Ciencias Sociales por la Universidad de Buenos Aires (UBA). Es docente universitaria e investigadora asistente del Consejo Nacional de Investigaciones Científicas y Técnicas (CONICET) en el Centro de Estudios e Investigaciones Laborales (CEIL). Agradezco especialmente los comentarios y observaciones realizados por los evaluadores anónimos del artículo. 


\section{Introducción}

E

fin del régimen de convertibilidad ${ }^{1}$ en Argentina abrió una etapa cuyas características económicas, sociales y políticas plantearon diversos contrapuntos respecto a la dinámica presentada durante los ańos noventa, cuando se consolidaron las políticas neoliberales. Luego de la profundización de la crisis económica y del deterioro en las condiciones de vida y de trabajo de las clases subalternas que siguieron a la devaluación del peso en enero de 2002, desde 2003 el crecimiento económico y el del empleo ${ }^{2}$ establecieron condiciones objetivas para la reemergencia de la conflictividad laboral, lo que se manifestó en una pérdida de gravitación de los movimientos de trabajadores desocupados frente a las organizaciones sindicales en la escena política.

En este marco se abrió un debate sobre la "revitalización" sindical que centró la mirada en los determinantes de la presencia sindical en la escena política. Uno de los indicadores estudiados para dar cuenta de ello ha sido la evolución de la negociación colectiva, sobre la cual tendió a priorizarse una mirada cuantitativa y general, resaltando el aumento de la cantidad de negociaciones, su dinámica y periodicidad, la ampliación de su cobertura, el incremento de las negociaciones a nivel de actividad y su función en la determinación salarial. Sobre esta base, algunos estudios destacaron las discontinuidades en relación con los años noventa (Etchemendy, y Collier, 2007; Palomino, y Trajtemberg, 2006; Palomino, 2008; Senén González, y Haidar, 2010), sin embargo, no se prestó suficiente atención ni a las características ni al contenido de la negociación colectiva en el periodo.

1 El régimen de convertibilidad se implementó en Argentina a partir de abril de 1991; fue una de las principales medidas impulsadas por el gobierno de Carlos Menem entre el conjunto de reformas estructurales de orientación neoliberal. El Plan de Convertibilidad, sancionado por ley del Congreso Nacional, establecía un nuevo signo monetario (el peso) —un tipo de cambio fijo en una relación 1 peso = 1 dólar-, y prohibía la indexación de contratos y la emisión monetaria sin un respaldo equivalente en divisas en el Banco Central de la República Argentina. En el contexto de la apertura comercial y liberalización financiera, esta medida favoreció un creciente déficit comercial en fases ascendentes del ciclo económico y supuso una economía altamente dependiente del flujo de capitales del exterior, o bien, como sucedió, del endeudamiento externo. Asimismo, se produjo el quiebre de numerosas empresas con la consecuente expulsión de trabajadores del mercado laboral. Como parte de la reestructuración neoliberal aumentó el desempleo, la precariedad laboral y la pobreza. El Plan de Convertibilidad, pieza clave en dicha reestructuración e, inicialmente, en el consenso generado en distintos sectores sociales por la estabilidad monetaria, estalló con la crisis económica, social y política de 2001.

2 El piB creció en el periodo 2003-2007 al 8.8\% anual promedio. Luego de la recesión de 2009, en 2010 y 2011 la economía retomó una elevada tasa de crecimiento respecto del ańo anterior, aunque volvió a descender en 2012. El empleo presentó una evolución destacada, principalmente durante los primeros años, y la tasa de desempleo abierto pasó del $21.5 \%$ de la población económicamente activa en mayo de 2002 al 7.3\% en el segundo semestre de 2011. Fuente: Encuesta Permanente de Hogares (EPH), Instituto Nacional de Estadísticas y Censos (INDEC). 
El propósito de este artículo es intervenir en la discusión sobre la "revitalización" sindical a partir del estudio de las características de la negociación colectiva y de los contenidos negociados. En primer lugar, se analizará qué se entiende por "revitalización" sindical en Argentina, con sus determinantes y principales características. En segundo, se desarrollan las características y contenidos de la negociación colectiva para interrogar sobre qué expresan en cuanto al protagonismo sindical en el periodo estudiado. Finalmente, se sintetizan las principales conclusiones del trabajo y se deja una serie de reflexiones para evaluar en estudios posteriores.

\section{La "revitalización" sindical en la Argentina reciente: condiciones y características}

\section{¿Retorno sindical?}

La acción sindical durante los gobiernos kirchneristas abrió un debate sobre la "revitalización" sindical en Argentina, concepto que daría cuenta de un recobrado protagonismo de los sindicatos en la escena política y laboral (Etchemendy, y Collier, 2007; Atzeni, y Ghigliani, 2008; Senén González, y Haidar, 2010).

Efectivamente, en los años 2004 y 2005 se observa un incremento de la conflictividad laboral caracterizada por un desplazamiento de los trabajadores desocupados y de los movimientos de desocupados como principales protagonistas, y de los reclamos por puestos de trabajo y planes sociales como demandas preponderantes. Los conflictos son crecientemente protagonizados por trabajadores ocupados, asumen una mayor centralidad las organizaciones sindicales, y predominan las reivindicaciones y demandas salariales. ${ }^{3}$

Etchemendy, y Collier (2007) sostienen que, desde 2003, se aprecia un resurgimiento sindical caracterizado por la emergencia de un "neocorporativismo segmentado". Este modelo se apartaría tanto del modelo neoliberal pro mercado como del corporativismo estatal imperante durante parte del siglo XX en países de América Latina y del sur de Europa, por una mayor autonomía respecto del Estado. También, a diferencia del neocorporativismo europeo, los sindicatos no se orientan hacia la gestión de las políticas sociales sino a "administrar" la puja distributiva, es decir, la disputa por la distribución del ingreso. El otro aspecto que introduce una diferencia con los países avanzados, radica en el carácter segmentado de la clase trabajadora, debido al tamaño del sector informal.

3 Sobre las características y dinámica del conflicto laboral durante la posconvertibilidad puede consultarse Cotarelo (2007); Atzeni, y Ghigliani (2008) y Eskenazi (2011). 
Ahora bien, los estudios que resaltan el recobrado protagonismo sindical corren el riesgo de invisibilizar su centralidad durante la década de 1990. Es preciso señalar que los sindicatos no estuvieron ausentes del conflicto laboral en aquellos años, aunque la articulación de las luchas en torno a los movimientos de trabajadores desocupados tuvo una mayor importancia. En la segunda mitad de esa década, distintas expresiones sindicales que combatían el neoliberalismo participaron activamente del conflicto social y laboral, como la Central de los Trabajadores Argentinos (CTA), la Corriente Clasista y Combativa (CCC) y el Movimiento de Trabajadores Argentinos (MTA), mientras la dirigencia de la Confederación General de Trabajadores (CGT), que negoció con los gobiernos menemista y aliancista las políticas de flexibilización laboral, optó por permanecer alejada de las calles, aunque no de la escena política y laboral. ${ }^{4}$

En este sentido, consideramos que el punto a destacar sobre el protagonismo sindical durante los años de la posconvertibilidad radica en que la CGT recupera un rol de disputa en el plano económico-corporativo. Más que retorno de los sindicatos, se observa una recobrada centralidad de la lucha sindical, es decir, de la lucha por las condiciones de compra-venta de la fuerza de trabajo.

Esta orientación se expresa en la corriente interna que asume la conducción de la central sindical hasta el año 2012, liderada por Hugo Moyano, dirigente del MTA y luego de la CGT "disidente" conformada en el año 2000, aunque no podemos dejar de señalar que el conjunto de los sindicatos nucleados en la CGT se ubicó detrás de esta dirección, conscientes del nuevo tiempo político. ${ }^{5}$

\section{Las condiciones económicas y políticas de la lucha sindical}

El protagonismo sindical en los años recientes se despliega sobre la base de un conjunto de condiciones objetivas, como el aumento del empleo en un ciclo de crecimiento económico, la profunda caída del salario real posterior a la devaluación de enero de 2002, ${ }^{6}$ y la configuración de una dinámica inflacionaria, pronunciada a partir de 2007. Sin embargo, estas condiciones objetivas no permiten explicar por sí mismas la dinámica de la conflictividad en el periodo. Para ello es preciso integrar las transformaciones políticas expresadas en la

4 Cabe considerar el análisis de Piva (2006), quien sostiene que durante la década de 1990 se produce un desacople entre los ciclos de conflictividad laboral y la acción de la cúpula sindical cegetista.

5 Previa a la fractura de la CGT de 2012, se oficializó una división en 2008, precisamente en el marco de la crisis política desencadenada entre el gobierno y la burguesía agropecuaria en torno a la aplicación de retenciones móviles a las exportaciones (Resolución 125/08), con la conformación de la cGT Azul y Blanca liderada por el gastronómico L. Barrionuevo.

6 La caída del salario real promedio se situó en torno al $30 \%$. 
insurrección popular de diciembre de 2001 y el modo en que la resistencia a una profundización del ajuste neoliberal permitió horadar el consenso que las reformas neoliberales habían logrado en amplias capas de la población durante la década de 1990.

En un nuevo escenario político y con la necesidad de construir un proyecto político hegemónico, el gobierno de Néstor Kirchner, iniciado en 2003, desplegó una política laboral orientada a contener y encauzar institucionalmente la conflictividad social que estalló en la crisis de 2001, con lo que favoreció la relegitimación de la CGT. Como indican Atzeni, y Ghigliani (2008), la reunificación de la CGT en 2004 expresó la apuesta gubernamental por el reempoderamiento de la tradicional central sindical frente a las organizaciones de trabajadores desocupados. Cabe apuntar, asimismo, que si bien contaron desde sus inicios con el apoyo de la СTA, hasta 2013 los distintos gobiernos kirchneristas le han negado la personería gremial.

Entre las políticas salariales más significativas puede mencionarse la convocatoria al Consejo Nacional del Empleo, la Productividad y el Salario Mínimo, Vital y Móvil para regular el salario mínimo, vital y móvil (sMvm) a partir de julio de 2003.

Cabe apuntar, a su vez, el fortalecimiento de la negociación colectiva. A través del decreto 392/2003, el gobierno dispuso la incorporación a los salarios básicos de las sumas no remunerativas ${ }^{7}$ que habían formado parte de la política salarial desde el gobierno de Eduardo Duhalde, con el fin de impulsar la canalización de las demandas salariales a través de mecanismos institucionalizados de las relaciones laborales. Si bien estas medidas propiciaron cierta recuperación salarial, los ingresos reales de los trabajadores permanecieron retrasados, mostrando significativas diferencias entre trabajadores registrados y no registrados en la seguridad social. Los asalariados registrados recuperaron recién en 2006 los niveles adquisitivos previos a la devaluación (históricamente bajos), mientras los salarios reales de los trabajadores no registrados permanecían levemente retrasados aún en 2010. Cabe apuntar que, así como determinadas medidas favorecieron cierta recuperación salarial, desde 2006, el gobierno ha tendido a establecer "de hecho" pautas que establecen un límite en la negociación paritaria. Si bien estas pautas han sido superadas por algunos gremios, fundamentalmente en 2010 y 2011, los acuerdos expresaron una alianza con la CGT en relación con la administración y contención de la puja distributiva.

Además de las condiciones económicas, laborales y políticas favorables a la "revitalización" sindical, los estudios destacan un conjunto de condiciones

7 Las sumas no remunerativas no se computan para el cálculo del aguinaldo, vacaciones, indemnizaciones y horas extra.

Perfiles Latinoamericanos | vol. 23, núm. 46, julio-diciembre de 2015 | Flacso México Clara Marticorena | "Revitalización” sindical y negociación colectiva en Argentina (2003-2011) | pp. 173-195 
institucionales (o político-institucionales) que habrían sobrevivido pese a las transformaciones operadas en los años noventa en las relaciones laborales y en la composición de la clase trabajadora, permaneciendo los elementos centrales del modelo sindical argentino configurado en el marco del ascenso del peronismo. Se destacan, al respecto, la Ley de Asociaciones Sindicales (Ley 23.551) y la Ley de Convenciones Colectivas de Trabajo (Ley 14.250). La primera establece la existencia de un monopolio de la representación a través del otorgamiento por parte del Estado de la personería gremial al sindicato con la mayor cantidad de afiliados en la actividad. Solo los sindicatos con personería gremial pueden representar colectiva e individualmente a los trabajadores del sector, es decir, que solo estos sindicatos se encuentran facultados para participar en la negociación colectiva. A su vez, el sindicato con personería es el que recauda las cuotas sindicales a través de las retenciones de los empleadores y el que administra las obras sociales. El sindicato con personería gremial, además, puede contar con delegados sindicales en el lugar de trabajo, quienes están cubiertos por la tutela sindical.

La Ley de Convenciones Colectivas de Trabajo establece, por su parte, la atribución estatal —en tanto autoridad de aplicación— de la homologación de convenios y acuerdos para que entren en vigencia; el principio de ultraactividad, es decir, que una vez vencida la convención colectiva sus cláusulas siguen vigentes hasta que las partes acuerden la celebración de otro convenio; y la cobertura "extensa" (erga omnes) de la negociación colectiva, es decir, que los convenios y acuerdos rigen para todos los trabajadores de la(s) actividad(es) para la(s) cual(es) rige la convención independientemente de su afiliación al sindicato firmante del convenio o acuerdo.

Si bien los sindicatos lograron evitar con éxito la modificación del monopolio de la representación y mantener el control de las obras sociales sindicales en los años noventa, en el año 2000, a través de la Ley 25.250, se legalizó un grave retroceso en el derecho colectivo del trabajo. Desde comienzos del gobierno de Menem se promovió la descentralización de la negociación colectiva con la habilitación de la elección del nivel de negociación (Decreto 2284/91), pero aquí tuvo un incentivo mayor, pues se permitió que convenios de empresa modificaran condiciones pactadas en convenios de actividad. A su vez, se limitó el principio de ultraactividad al establecer un procedimiento de renegociación de convenios ultraactivos correspondientes a las rondas de negociación de 1975 y 1988.

Estas condiciones fueron modificadas durante el gobierno kirchnerista. En 2004 se promulgó la Ley de Ordenamiento Laboral núm. 25.877, que restituyó plenamente el principio de ultraactividad, otorgó de nuevo preeminencia a las negociaciones colectivas de ámbito mayor sobre las negociaciones de ámbito menor, y revirtió las disposiciones que, en esta materia, habían sido legisladas 
en el marco de la crisis de la convertibilidad. Estos dos aspectos fueron importantes en relación con la mayor centralidad y gravitación de la CGT en la regulación de las condiciones salariales y laborales ya que restituyeron dos factores de poder para la tradicional organización sindical.

\section{Alcances y límites de la organización sindical}

El protagonismo sindical reciente se explicaría, asimismo, por el mantenimiento de una relativamente elevada tasa de sindicalización, pese al deterioro de las condiciones del mercado de trabajo en las últimas décadas del siglo xx. Atzeni, y Ghigliani (2008) apuntan que, si bien en las décadas de 1980 y 1990 se redujo la cantidad de afiliados debido al aumento del desempleo y del empleo no registrado, el porcentaje de trabajadores sindicalizados sobre los trabajadores ocupados en condiciones de sindicalizarse no disminuyó drásticamente. La tasa de sindicalización se habría ubicado en el 41\% para el periodo 1982-1983; en 44\% en 1989; 47\% en 1990, y en el 42\% para 2001.

La información presentada por Senén et al. (2010a) plantea, sin embargo, una significativa caída en la tasa de sindicalización a lo largo de los noventa. El indicador de densidad sindical pasó del 65.6\% en 1990 al 38.7\% en 1995 y al $31.7 \%$ en 2000. Por su parte, información del Módulo de Relaciones Laborales de la Encuesta de Indicadores Laborales ${ }^{8}$ situaba la tasa de sindicalización para 2005 en 37.2\% (Trajtemberg et al., 2005). Estos resultados indican que en los años recientes se produce una recuperación de la tasa de sindicalización, sin embargo, esta no alcanza los niveles que presentaba a comienzos de la década de 1990. Cabe reparar en que tales estimaciones se construyen considerando al universo de los trabajadores formales, de modo que si se contabilizaran los trabajadores no registrados en la seguridad social, la tasa disminuiría considerablemente.

Los niveles de sindicalización en Argentina han sido históricamente elevados e incluso hoy pueden valorarse como altos en un análisis comparativo a nivel internacional. Marshall (2006) señala entre los principales aspectos que explican los niveles de afiliación en Argentina la presencia de delegados sindicales en los lugares de trabajo y la prestación de servicios de salud por la administración de las obras sociales. También destaca la generalización de los aportes al sindicato

8 La Encuesta de Indicadores Laborales (EIL) del Ministerio de Trabajo, Empleo y Seguridad Social de la Nación (MTESs) revela datos del sector formal de la economía, en empresas de más de diez empleados, de todas las ramas de actividad excepto del sector primario para cinco aglomerados urbanos (Gran Buenos Aires, Gran Mendoza, Gran Rosario, Gran Córdoba y Gran Tucumán). 
para los trabajadores beneficiarios del convenio colectivo, aún sin encontrarse afiliados, contenido que ha tenido particular difusión en los años recientes. ${ }^{9}$

En cuanto a la presencia sindical en los lugares de trabajo, las pocas estimaciones disponibles sugieren que posee un carácter limitado en términos agregados, aunque presenta significativas diferencias según el tamaño de los establecimientos. Según Trajtemberg et al. (2005), en 2005 tan solo en el 12.4\% del total de empresas relevadas había presencia de delegados sindicales; porcentaje que se mantuvo para 2006 (Trajtemberg et al., 2008). De todos modos, cabe señalar que en los establecimientos de mayor tamaño (de más de doscientos trabajadores) la presencia de delegados ascendía a 61.1\%; en los establecimientos medianos (de entre cincuenta y doscientos trabajadores) era del $31 \%$, mientras que solo el $7.5 \%$ de los pequeños establecimientos (de diez a cincuenta trabajadores) contaba con la presencia de delegados (Trajtemberg et al., 2008: 29).

\section{Clivajes inter e intrasindicales}

Estos elementos permiten evaluar el alcance de la organización sindical de la clase trabajadora, pero no resultan suficientes si no contemplamos las características del reciente protagonismo sindical.

Las características asumidas por algunos conflictos laborales de significativa repercusión y resonancia (por ejemplo, los del Hospital Garraham, los de Subterráneos de Buenos Aires, o los de Kraft-Terrabusi) presentaron distintas grietas en la representación sindical, lo cual puso de manifiesto diversas divisiones internas, particularmente, entre comisiones internas y organizaciones gremiales de base y conducciones sindicales (Meyer, y Gutiérrez, 2005; Castillo, 2007; Varela, 2010 y 2013). El análisis de Cotarelo (2007) apunta a que, si bien una gran mayoría de los conflictos fue dirigida por la CGT y CTA, se aprecian elementos que expresan un cuestionamiento a estas direcciones sindicales y que se orientan a la búsqueda de conducciones alternativas, antiburocráticas y clasistas. $\mathrm{Al}$ respecto, Varela (2013) señala que el "retorno de la cuestión sindical" en los años de la posconvertibilidad asumió una doble forma, que involucra no solo la centralidad de las cúpulas sindicales tradicionales sino también un surgimiento y una dinamización de comisiones internas y cuerpos de delegados en los lugares de trabajo, con lo que experiencias de sindicalismo de base fueron conformadas.

También asistimos, en estos años, al desarrollo de distintos conflictos intersindicales por el encuadramiento de los trabajadores, los cuales poseen diversas aristas. Por un lado, en el reclamo por encuadramiento, los trabajadores cubier-

$9 \mathrm{Al}$ respecto se sugiere consultar Observatorio del Derecho Social (s/f) y a Marshall, y Perelman (2008). 
tos por convenios reivindican un convenio colectivo que regula mejores condiciones salariales y de trabajo que las propias. En algunos casos, el conflicto por encuadramiento busca volver a integrar dentro del personal comprendido en la convención colectiva de trabajo a grupos de trabajadores relegados en anteriores negociaciones, como resultado del proceso de exclusión de categorías de convenio desarrollado fundamentalmente durante los años noventa. ${ }^{10}$ Por otro lado, los conflictos por encuadramiento suponen un conflicto por la administración de recursos entre distintas organizaciones sindicales, en tanto la ampliación de las categorías de trabajadores representados por un sindicato implica un incremento en las cuotas por obra social, aportes solidarios y, potencialmente, por afiliación. Por último, en estos conflictos interviene el Ministerio de Trabajo, Empleo y Seguridad Social, el cual determina el encuadramiento.

De este modo, en el periodo, la recobrada centralidad de la lucha sindical está liderada por las organizaciones sindicales tradicionales, pero se encuentra atravesada por disputas intrasindicales (entre organizaciones de base y dirigentes gremiales) e intersindicales (entre distintas dirigencias sindicales).

\section{La negociación colectiva en tiempos de "revitalización" sindical}

\section{Características generales}

Diversos autores (Etchemendy, y Collier, 2007; Senén, y Haidar, 2010, y Senén et al., 2010b) resaltan el aumento de la cantidad de negociaciones colectivas, la ampliación de su cobertura y el incremento de negociaciones a nivel de actividad, planteando así un "retorno" a la negociación centralizada y subrayando las diferencias en la evolución de la negociación colectiva reciente respecto a la década de 1990. Detengamos nuestra mirada en la evolución, cobertura y nivel de la negociación colectiva.

Considerando convenios colectivos de trabajo y acuerdos, la evolución de la cantidad de negociaciones se incrementó sustancialmente en el periodo 20042011 en relación con los niveles de la década de 1990 (cuadro 1). El aumento de la cantidad de negociaciones debe considerar, de todos modos, la centralidad del contenido salarial, reflejada en el predominio de acuerdos frente a la negociación de convenios colectivos de trabajo. ${ }^{11}$ Efectivamente, como analizaremos

10 Para un análisis sobre la evolución de las categorías socioprofesionales en la negociación colectiva puede consultarse Marticorena (2012).

11 Según Novick, y Trajtemberg (2000: 1) mientras los convenios colectivos de trabajo constituyen "[...] cuerpos completos de normas que regulan el conjunto de las relaciones laborales", los acuerdos son ne- 
más adelante, la discusión paritaria estuvo enfocada en la negociación de salarios nominales, con lo que otras condiciones de trabajo fueron desplazadas. Los datos permiten observar que esta dinámica se pronunció a partir de 2008, justamente cuando se produjo una aceleración del ritmo inflacionario.

Cuadro 1. Evolución de la cantidad de negociaciones colectivas* y distribución por tipo de negociación ${ }^{\star *}(1991-1998 / 2002-2011)$

\begin{tabular}{lcccc}
\hline Año & Cantidad negociaciones & Convenio (\%) & Acuerdo (\%) & Total (\%) \\
\hline 1991 & 97 & 5.2 & 94.8 & 100 \\
1992 & 209 & 11.0 & 89.0 & 100 \\
1993 & 218 & 22.5 & 77.5 & 100 \\
1994 & 202 & 29.7 & 70.3 & 100 \\
1995 & 196 & 35.7 & 64.3 & 100 \\
1996 & 152 & 44.1 & 55.9 & 100 \\
1997 & 208 & 29.8 & 70.2 & 100 \\
1998 & 219 & 39.7 & 60.3 & 100 \\
& & & & \\
2002 & 208 & 41.9 & 58.1 & 100 \\
2003 & 406 & 32.7 & 67.3 & 100 \\
2004 & 348 & 25.3 & 74.7 & 100 \\
2005 & 568 & 18.4 & 81.6 & 100 \\
2006 & 930 & 15.0 & 85.0 & 100 \\
2007 & 1027 & 14.4 & 85.6 & 100 \\
2008 & 1231 & 8.3 & 91.7 & 100 \\
2009 & 1331 & 6.4 & 93.6 & 100 \\
2010 & 2038 & 6.5 & 93.5 & 100 \\
2011 & 1864 & 5.7 & 94.3 & 100 \\
\hline
\end{tabular}

Fuentes: * González et. al (2010b) y Boletín de Estadísticas Laborales, Ministerio de Trabajo, Empleo y Seguridad Social (BEL-MTESS), disponible en <http://www.trabajo.gob.ar/left/estadisticas/bel/index.asp>. ** Para el periodo 1991-1998, Atzeni, y Ghigliani (2008); para el periodo 2002-2009, Observatorio del Derecho Social de la CTA; para 2010 y 2011, Medina et al. (2012).

El aumento de la negociación colectiva estuvo acompańado, por cierto, por un incremento del personal comprendido, que ascendió de 1222000 asalariados en 2004 a 4235000 en 2011 (cuadro 2). Ahora bien, para poder hablar de un aumento de la cobertura de la negociación colectiva es preciso analizarla en relación con la evolución del empleo. Si consideramos los datos absolutos del empleo asalariado correspondientes al total urbano estimado por el Ministerio de Trabajo (MTESs), es posible apreciar que el personal comprendido en la negociación colectiva aumenta más que el empleo asalariado total y que el

gociaciones que modifican parcialmente el contenido de un convenio colectivo de trabajo, por ejemplo, precisando o adecuando una cláusula específica o incorporando correcciones salariales. 
empleo asalariado registrado entre 2004 y 2007. Sin embargo, la evolución se desacelera a partir de 2007, incluso más que la desaceleración observable en el aumento del empleo asalariado y, fundamentalmente, del empleo registrado, con la excepción del año 2010.

Cuadro 2. Cobertura de la negociación colectiva

\begin{tabular}{ccccccc}
\hline Año & $\begin{array}{c}\text { Personal } \\
\text { comprendido en } \\
\text { la negociación } \\
\text { colectiva (NC) }\end{array}$ & $\begin{array}{c}\text { Tasa de variación } \\
\text { interanual del } \\
\text { personal compren- } \\
\text { dido en NC }\end{array}$ & $\begin{array}{c}\text { Empleo } \\
\text { asalariado } \\
\text { total* }\end{array}$ & $\begin{array}{c}\text { Tasa de varia- } \\
\text { ción interanual } \\
\text { del empleo } \\
\text { asalariado total }\end{array}$ & $\begin{array}{c}\text { Empleo } \\
\text { asalariado } \\
\text { registrado* }\end{array}$ & $\begin{array}{c}\text { Tasa de variación } \\
\text { interanual del } \\
\text { empleo asalariado } \\
\text { registrado }\end{array}$ \\
\hline 2004 & 1222000 & - & 9184092 & - & 4503818 & - \\
2005 & 2117000 & $73.2 \%$ & 9778841 & $6.5 \%$ & 5078193 & $12.8 \%$ \\
2006 & 3500000 & $65.3 \%$ & 10432390 & $6.7 \%$ & 5912019 & $16.4 \%$ \\
2007 & 3938000 & $12.5 \%$ & 10932133 & $4.8 \%$ & 6585194 & $11.4 \%$ \\
2008 & 3992000 & $1.4 \%$ & 11234499 & $2.8 \%$ & 7143459 & $8.5 \%$ \\
2009 & 4001388 & $0.2 \%$ & 11337689 & $0.9 \%$ & 7334003 & $2.7 \%$ \\
2010 & 4220161 & $5.5 \%$ & 11541554 & $1.8 \%$ & 7528876 & $2.7 \%$ \\
2011 & 4235000 & $0.4 \%$ & 11892788 & $3.0 \%$ & 7875618 & $4.6 \%$ \\
\hline
\end{tabular}

${ }^{*}$ Corresponde al total urbano estimado por el MTESS.

Fuente: Elaboración propia con base en BEL (MTESS).

Es posible observar esta evolución del personal comprendido en la negociación colectiva en relación con la evolución del empleo en el gráfico 1.

Gráfico 1. Evolución del personal comprendido en la negociación colectiva (NC) en relación con el empleo asalariado total y el empleo asalariado registrado, 2004-2011

(en porcentajes)

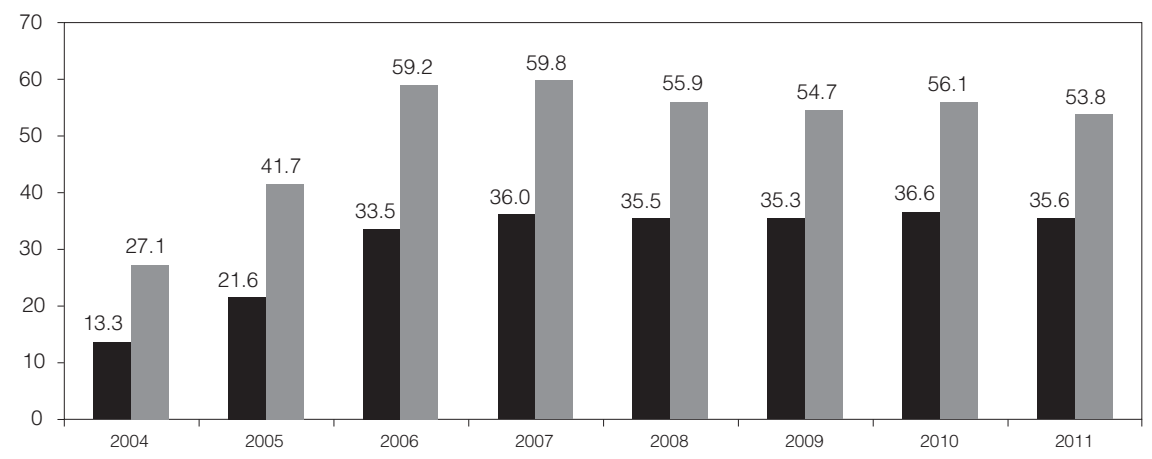

- Personal comprendido NC/Empleo asalariado total

- Personal comprendido NC/Empleo asalariado registrado

Fuente: Elaboración propia con base en BEL (MTESS). 
En el gráfico 1 se aprecia que la cobertura de la negociación colectiva presenta un amesetamiento en lo que se refiere a empleo asalariado total desde 2007, mientras que en el empleo asalariado registrado se observa una disminución de la cobertura respecto al porcentaje alcanzado en dicho año.

Analicemos qué sucede en cuanto al nivel de negociación: comparemos su evolución reciente con anteriores rondas de negociación colectiva (cuadro 3). Avalando las tesis sobre el retorno de la negociación centralizada, puede apreciarse un aumento de las negociaciones a nivel de actividad. Sin embargo, este aumento no revierte el predominio de negociaciones celebradas a nivel de empresa, lo que marca una línea de continuidad en las tendencias inauguradas con el avance de las políticas neoliberales en los años noventa y consolida una fuente de heterogeneidad en las condiciones laborales y salariales.

Cuadro 3. Convenios y acuerdos según el nivel de negociación en distintos periodos.

\begin{tabular}{l|ccc|ccc}
\hline \multirow{2}{*}{ Periodo } & Empresa & Actividad & Total & Empresa & Actividad & Total \\
\cline { 2 - 7 } & \multicolumn{5}{c}{ Cantidad } & \multicolumn{3}{c}{ Porcentaje } \\
\hline 1975 & 167 & 456 & 623 & 26.8 & 73.2 & 100 \\
$1988-1991^{*}$ & 42 & 174 & 216 & 19.4 & 80.6 & 100 \\
$1991-1994$ & 268 & 448 & 716 & 37.4 & 62.6 & 100 \\
$1995-1999$ & 676 & 206 & 882 & 76.6 & 23.4 & 100 \\
2004 & 236 & 112 & 348 & 67.8 & 32.2 & 100 \\
2005 & 365 & 203 & 568 & 64.3 & 35.7 & 100 \\
2006 & 605 & 325 & 930 & 65.1 & 34.9 & 100 \\
2007 & 691 & 336 & 1027 & 67.3 & 32.7 & 100 \\
2008 & 795 & 436 & 1231 & 64.6 & 35.4 & 100 \\
2009 & 935 & 396 & 1331 & 70.2 & 29.8 & 100 \\
2010 & 1456 & 582 & 2038 & 71.4 & 28.6 & 100 \\
2011 & 1339 & 525 & 1864 & 72.0 & 28.0 & 100 \\
\hline *Hasta & 1991 & &
\end{tabular}

*Hasta Junio de 1991

Fuentes: Elaboración propia con base en Battistini (2000), Novick, y Trajtemberg (2000), y BEL, MTESS.

De este modo, persisten diversas formas de fragmentación de la clase trabajadora que, lejos de ser compensadas, son vehiculizadas a través de la negociación colectiva. El peso de la negociación por empresa y la convivencia en un mismo establecimiento de trabajadores de planta, contratados y tercerizados ${ }^{12}$

12 Por trabajadores de planta entendemos quienes forman parte estable de las empresas y cuya modalidad de contratación es formal y por tiempo indeterminado. Por trabajadores contratados nos referimos a trabajadores que se encuentran bajo modalidades de contratación por tiempo determinado y, por tanto, tienen una mayor inestabilidad laboral. Los trabajadores tercerizados son aquellos contratados por una empresa a través de otra para que presten servicios en la primera. 
profundiza la fragmentación de la clase a partir de la heterogeneidad de situaciones entre trabajadores cubiertos por distintos convenios. A ello es preciso sumar, por cierto, la heterogeneidad y la dispersión que supone la persistencia de un alto porcentaje de trabajadores no registrados en la seguridad social. ${ }^{13}$

\section{Los contenidos negociados}

Según la hipótesis de la emergencia de un nuevo régimen de empleo en la Argentina de la posconvertibilidad (Palomino, y Trajtemberg, 2006; Palomino, 2008), se esperaría que el "resurgimiento" sindical en la última década se expresara en una reversión de los contenidos de flexibilización laboral incorporados en la negociación colectiva durante los años noventa, como consecuencia del disciplinamiento operado sobre los trabajadores y sus organizaciones. A pesar de la importancia que reviste, el análisis del contenido de la negociación colectiva durante el periodo reciente tendió a permanecer ausente de los debates sobre revitalización sindical y negociación colectiva.

Diversos estudios han señalado la permanencia de contenidos ligados a la flexibilidad laboral en la negociación colectiva del periodo (Observatorio del Derecho Social, 2008; Marticorena, 2010; Soul, 2011; Guevara, 2012). Por flexibilización laboral entendemos todos aquellos aspectos que permitan un mayor control patronal de las formas de compra-venta y uso de la fuerza de trabajo: la posibilidad de modificar la organización del tiempo de trabajo y la asignación de tareas; flexibilizar las condiciones salariales articulándolas con distintos incentivos por "desempeño", productividad y cumplimiento de objetivos; formas de contratación por tiempo determinado, personal tercerizado o contratado por agencias como estrategia permanente de "regulación" del plantel de trabajadores en función de la demanda, entre otras. ${ }^{14}$

El análisis de acuerdos y convenios colectivos en sectores seleccionados de la industria manufacturera ${ }^{15}$ evidenció: a) la vigencia de modalidades de

13 El porcentaje de asalariados no registrados en la seguridad social ascendió en 2003 al 49.5\% (IV trimestre de 2003). Desde 2004 presentó una tendencia descendente que se vio fuertemente desacelerada a partir de 2008. En el IV trimestre de 2012 ascendía al 34.6\% de los asalariados. Fuente: Información Económica al Día, Ministerio de Economía con base en Encuesta Permanente de Hogares, disponible en <http://www.mecon.gov.ar/peconomica/basehome/infoeco.html>.

14 Para un análisis detallado acerca de esta noción puede consultarse Marticorena (2010).

15 Las conclusiones presentadas aquí se basan en el análisis de convenios colectivos de trabajo (ССT) y acuerdos de diversos sectores de la industria manufacturera (alimentación, aceitero, panadero, químico y petroquímico, textil, vestido y automotriz) y de entrevistas semiestructuradas (un total de quince) a representantes patronales, sindicales y funcionarios del Ministerio de Trabajo que participan de los procesos de negociación colectiva. Como se aclara en los respectivos cuadros, se analizaron 32 convenios 
flexibilización contractual a partir de la utilización de contratos de trabajo por tiempo determinado (temporario, eventual o por obra); b) la permanencia de condiciones flexibles en cuanto a la distribución y organización del tiempo de trabajo lo que permitió extender o reducir las jornadas en función de la demanda de producción, evitando así el pago de horas extraordinarias, el mantenimiento de formas de organización y división de tareas basadas en la rotación de los trabajadores y la polivalencia funcional, y al desplazamiento del criterio de antigüedad para la promoción y cobertura de vacantes, entre otros aspectos. También cabe señalar las continuidades relativas a la composición salarial atando su evolución a la productividad —individual o grupal—, al desempeño y a la competencia.

Cuadro 4. Convenios colectivos de trabajo según principales contenidos negociados (1991-2002 / 2003-2007)

\begin{tabular}{|c|c|c|c|}
\hline \multirow{3}{*}{ Dimensiones } & \multirow{3}{*}{ Contenidos } & $1991-2002$ & 2003-2007 \\
\hline & & \multicolumn{2}{|c|}{ Total negociaciones } \\
\hline & & 32 & 34 \\
\hline \multirow{3}{*}{ Contratación } & Modalidades promovidas / de fomento del empleo* & 14 & - \\
\hline & $\begin{array}{l}\text { Modalidades por tiempo determinado (eventual, } \\
\text { por temporada, por obra) }\end{array}$ & 6 & 14 \\
\hline & Periodo de prueba & 14 & 18 \\
\hline \multirow{3}{*}{$\begin{array}{l}\text { Componentes } \\
\text { salariales }\end{array}$} & Plus asistencia / Puntualidad / Contracción al trabajo & 18 & 22 \\
\hline & Plus por productividad / objetivo & 19 & 18 \\
\hline & Componentes no remunerativos (beneficios sociales) & 12 & 12 \\
\hline \multirow{3}{*}{ Tiempo de trabajo } & Jornada promedio*^ / Extensión o reducción de jornada & 20 & 16 \\
\hline & Turnos rotativos & 16 & 15 \\
\hline & Espera del relevo & 11 & 8 \\
\hline \multirow{2}{*}{$\begin{array}{l}\text { Organización del } \\
\text { trabajo }\end{array}$} & Polivalencia / Tarea diversificada & 24 & 18 \\
\hline & Trabajo por equipos & 15 & 11 \\
\hline Promoción & $\begin{array}{l}\text { Desplazamiento del criterio de antigüedad para cubrir } \\
\text { vacantes }\end{array}$ & 16 & 16 \\
\hline
\end{tabular}

*Se trata de modalidades por tiempo determinado que fueron incluidas durante los años noventa en el marco de las reformas a la legislación laboral. Estas modalidades fueron derogadas en 1998 por la Ley 25.013.

** La posibilidad de establecer jornadas promedio se incorporó por Ley 24.013 de 1991, contenido que continúa vigente. Permite establecer un total de horas mensuales o, incluso, anuales de tal manera que se genera un sistema de "crédito y débito", por el cual una caída en el nivel de actividad y, por tanto, de horas trabajadas, se traduce en una "deuda" del trabajador con la empresa, tiempo de trabajo que deberá compensar cuando la empresa lo requiera, en muchos casos, sin abonar los correspondientes adicionales por trabajo en fines de semana ni horas extra.

Fuente: Elaboración propia con base en convenios colectivos de trabajo analizados.

colectivos celebrados entre 1991 y 2002, y 34 celebrados entre 2003 y 2007. Los acuerdos, por su parte, corresponden fundamentalmente al periodo 2004-2007. La selección buscó tomar los principales convenios de cada actividad y analizar las negociaciones articuladas con los mismos a lo largo del periodo estudiado. Se ha extendido el análisis de los convenios colectivos de trabajo celebrados en las actividades seleccionadas para el periodo 2008-2011 aunque, dada la poca cantidad, que asciende a un 
Cabe detenernos en el estudio de las condiciones salariales. Pese a constituir uno de los contenidos principales de la negociación colectiva en estos años, sus características han sido poco atendidas. A partir del análisis realizado, es posible observar que inicialmente los aumentos del salario nominal incorporaron las sumas no remunerativas establecidas por los decretos estatales que formaron parte de la política salarial desplegada desde 2002, incorporándose al salario básico a partir del decreto 392/03. ${ }^{16}$ Esta incorporación se configuró en cuotas y, si bien el aumento de los salarios básicos fue determinando progresivamente los niveles salariales de los trabajadores registrados, el otorgamiento de sumas no remunerativas mantuvo una importante vigencia. Incluso, en diversos casos se conceden sumas de carácter remunerativo que no se incorporan al básico de convenio, quedando así fuera de la base de cálculo de distintos premios o beneficios que se estiman como porcentaje de dicho salario (por ejemplo, la antigüedad). También, entre los contenidos salariales, se destacan los premios o gratificaciones extraordinarias o sumas dadas "por única vez".

Cuadro 5. Acuerdos según principales contenidos salariales negociados (2004-2007)

\begin{tabular}{|c|c|c|}
\hline Contenidos salariales & $N$ & Porcentaje sobre el total \\
\hline Aumento del salario básico & 57 & 79.2 \\
\hline Absorción de aumentos / adicionales anteriores & 29 & 40.3 \\
\hline Sumas en cuotas o etapas & 27 & 37.5 \\
\hline Suma extraordinaria no remunerativa & 20 & 27.8 \\
\hline Aumento no remunerativo & 15 & 20.8 \\
\hline Aumento remunerativo no integrado al básico & 14 & 19.4 \\
\hline Sumas a cuenta de futuros aumentos & 13 & 18.1 \\
\hline Bonificación por antigüedad & 12 & 16.7 \\
\hline Bonificación por turno & 7 & 9.7 \\
\hline Premio por presentismo* & 6 & 8.3 \\
\hline Premio por productividad & 6 & 8.3 \\
\hline $\begin{array}{l}\text { Explicita no absorción de futuros aumentos y/o ya } \\
\text { otorgados }\end{array}$ & 4 & 5.6 \\
\hline Premio por función & 3 & 4.2 \\
\hline Suma extraordinaria remunerativa & 2 & 2.8 \\
\hline Total de acuerdos analizados (2004-2007) & 72 & 100 \\
\hline
\end{tabular}

total de diez сст, no se han incluido en el cuadro 4. En el caso de las actas acuerdo, si bien la actualización aún no ha sido concluida, permite apreciar las características señaladas en este artículo.

16 El Decreto 392/03 dispuso que se incorporara al salario básico la suma de \$224 en ocho cuotas de \$28, dando carácter remunerativo a las sumas otorgadas a través de los decretos 2641/02 y 905/03. 
El análisis de las características asumidas por la negociación salarial permitió apreciar el peso de la absorción de sumas percibidas por los trabajadores en los primeros años, que no solo incorporó las sumas no remunerativas dispuestas por el Poder Ejecutivo nacional sino también otros adicionales otorgados previamente por las empresas. Es preciso recordar que la evolución de los salarios se vio limitada a partir de 2006 en virtud de la conformación de una pauta salarial, como modo de limitar las conquistas salariales de los trabajadores en el marco de un aumento del conflicto laboral y la puja distributiva. En este marco, la "absorción de sumas otorgadas" pierde peso y asume mayor importancia la negociación de "sumas a cuenta de futuros aumentos". A su vez, se afianza la modalidad de la negociación de aumentos en cuotas, entre 3 y 4.

Es preciso señalar que la negociación salarial no estuvo ajena a (e incluso muchas veces se basó en) procesos de intensificación del tiempo de trabajo y de reorganización de tareas, implicando una mayor carga laboral. Conviene resaltar, a propósito de la intensificación del tiempo de trabajo y la definición de tareas, un fragmento de la entrevista realizada a un dirigente del gremio textil, que menciona la negociación salarial "a cambio" de una mayor carga de trabajo:

Entrevistado: [...] conflicto tuvimos uno muy grande en Reconquista por un problema de categorías y una producción, que lo fuimos manejando, hasta que fuimos con el secretario de interior hace veinte días, veinticinco días y lo arreglamos. Realmente conseguimos más de lo que esperábamos, porque la fábrica es de uno de los directivos de FITA y acá no nos pusimos de acuerdo. Este hombre es ingeniero, pero allá hablamos con los dueños en Reconquista y arreglamos más de lo quería la gente en realidad. Porque ellos querían un $20 \%$ de producción y nosotros le arreglamos hasta el 30 de noviembre quinientos pesos más cada uno aparte del Convenio Nacional por mes y hacer el estudio del premio que está el técnico de nosotros está allá armando con un técnico de la fábrica están armando un sistema de premios que en algunos caso se da y en otros no, por ahí no da para $[\ldots]$ pero bueno.

Pregunta: ¿Analizan los ritmos de producción?

Entrevistado: Claro, cuántas máquinas atiende, si tiene ayudante, si no tiene ayudante. Entonces se le habla a la gente, "mirá hemos conseguido esto pero en vez de dos máquinas tenés que atender dos máquinas y media, de cinco máquinas en vez de tres maquinistas va a haber dos, pero a cambio de eso [...] Pero lo estudiamos para que no represente un mayor esfuerzo para la gente, porque si no después no sirve, no da resultado. Se va manejando así".

Entrevista realizada en mayo de 2011. 
En el mismo sentido, considerando los mayores salarios de las grandes empresas del sector químico y petroquímico, una funcionaria del MTESS mencionaba:

[...] las empresas lo que van a necesitar son los turnos y las jornadas. En los turnos rotativos, cuando vos tenés una empresa que implementa un turno rotativo tiene que mejorar sensiblemente el salario, mejora sensiblemente el salario. Entonces, acá hablaba, cuando fue la negociación salarial de una empresa, una de las empresas más importantes químicas, que su salario promedio es de nueve mil pesos, se habla [...] otras, PYME, tienen 2068 pesos de inicial pero la grande tiene nueve mil pesos de promedio y tiene salarios de hasta once [...] Pero, es un trabajador que hace turnos rotativos, que hace diez mil millones de horas extra [...] y le pagan bien, está bien, pero [...] ése es el tema. Lo salarial, la mejora salarial es consecuencia de la modificación de turnos $[\ldots]$

Entrevista realizada en julio de 2010

Efectivamente, si bien la negociación salarial permitió a los trabajadores registrados recuperar - aunque tardíamente- los niveles adquisitivos previos a la devaluación, la evolución del costo laboral real vis à vis la evolución de la productividad ha quedado retrasada, indicando un margen de ganancias superior al de los ańos de la convertibilidad. ${ }^{17}$

Cabe señalar que, a medida que fue consolidándose la tendencia descendente del desempleo y relajándose su efecto disciplinador sobre los trabajadores ocupados, se observa una dinamización de la puja distributiva entre capital y trabajo que ha configurado una disputa por estrechar-ensanchar los límites de la explotación. Es en este contexto que la clase trabajadora logró instalar determinados temas en la agenda de discusión como la tercerización laboral y la composición salarial.

$\mathrm{Al}$ respecto, fue posible apreciar cambios puntuales en algunas negociaciones, por ejemplo, sobre condiciones de contratación y en el uso del tiempo de trabajo. Si bien se despliegan sobre la base del profundo disciplinamiento operado en las últimas décadas del siglo xx sobre los trabajadores, también indican la conquista de límites a la disponibilidad de la fuerza de trabajo por parte del capital. Un claro ejemplo de estos cambios puntuales, y de su emplazamiento sobre la base del retroceso previo, radica en que, si bien en algunos convenios se aprecia la

17 Al respecto véanse Marticorena (2013), Amar, Pastrana, y Villafañe (2010), y Michelena (2009). La evolución de la distribución funcional del ingreso puede darnos una aproximación a estas condiciones. Según estimaciones de Fernández, y González (2012), la participación de la masa salarial en el valor agregado bruto se encontraba en el año 2010 en niveles inferiores a los de comienzos de los años noventa (en 2010 era de $37.8 \%$, frente al 42.8\% de 1993). 
equiparación de condiciones laborales para trabajadores estables y temporarios o subcontratados, dichas modalidades de abaratar los costos de contratación y despido mantienen una extendida presencia. Asimismo, en algunos casos se observó ciertos cambios sobre las disposiciones relativas a suplencias en categorías superiores, sin modificar otros contenidos que facilitan o viabilizan la movilidad de los trabajadores entre tareas. Estas condiciones, aunque puntuales, disputan el avance patronal previo y se expresan en los contenidos negociados, tanto en los avances puntuales de los trabajadores como en la significativa presencia de la cláusula de paz social en las negociaciones colectivas. El análisis de los convenios colectivos celebrados en las actividades seleccionadas de la industria manufacturera en el periodo 2008-2011, un total de diez, permitió observar, en tres casos, como aspecto novedoso de las negociaciones entre las partes, la inclusión de los delegados sindicales de planta en las comisiones de seguimiento del convenio, o la mención explícita de sus funciones en el cumplimiento del convenio. ${ }^{18}$

Cabe apuntar aquí que si bien los contenidos de la negociación colectiva, sus cambios y continuidades, pueden constituir indicadores de la relación de fuerzas entre capital y trabajo, los temas en discusión en el marco de los conflictos laborales y de la negociación colectiva también pueden dar cuenta de la posición relativa de "los contendientes".

En este punto, las entrevistas realizadas permitieron observar que los reclamos sindicales tendieron a organizarse en torno a la centralidad de la problemática salarial y los beneficios por antigüedad, presentismo, o bien, se concentraron en reivindicaciones relativas a la definición de categorías, la carrera y la capacitación. El eje principal de los reclamos es de tipo salarial, aunque también refiere a las formas de contratación, como es el caso de los contratos de trabajo temporarios. Entre los empresarios, se observa una mayor preocupación por la productividad y diversas formas de flexibilidad. A su vez, las entrevistas realizadas revelaron la alerta del empresariado frente a la conflictividad laboral y la organización de los trabajadores, alerta que expresa la resistencia patronal a la pérdida — por menor que sea- del amplio poder de disciplinamiento laboral consolidado durante los años noventa.

\section{Reflexiones finales}

A lo largo de este trabajo se ha buscado plantear algunos ejes centrales de los análisis sobre la "revitalización" sindical en la Argentina reciente y se ha presen-

18 Se trata del сст 1235/2011 E de la empresa Basf (sector químico y petroquímico), del сст 1039/2009 E de la empresa DuPont y del сст 1159/10 E de la empresa Tipoiti (ambas del sector textil). 
tado una serie de contrapuntos a partir de una investigación propia acerca de las características de la negociación colectiva en el periodo en estudio.

Como ya quedó dicho, los estudios centrados en el análisis de la negociación colectiva como indicador de un "renovado" protagonismo sindical priorizaron su evolución cuantitativa sin indagarla detalladamente a partir del tipo y nivel de negociación. La incorporación de estas dimensiones demuestra el carácter eminentemente salarial de las negociaciones y la consolidación de estas a nivel de empresa desde los años noventa, pese a su aumento a nivel de actividad, con las consecuencias que ello representa para la heterogeneidad en las condiciones de trabajo y salario. Asimismo, el análisis de la cobertura de la negociación colectiva en relación con el nivel de empleo constata un aumento hasta el año 2007, al cual siguió una significativa desaceleración en la variación del personal comprendido en la negociación.

A su vez, este trabajo introdujo un aspecto central que ha sido desplazado en el debate sobre el "resurgimiento" o "revitalización" sindical, particularmente, en el análisis de los contenidos negociados y de las características de la negociación salarial. El estudio del contenido de la negociación colectiva descubre el carácter centralmente económico de las reivindicaciones sindicales y la permanencia de diversos puntos centrales de la flexibilización laboral que avanzó en los años noventa. La recobrada centralidad de la lucha sindical en Argentina no se ha visto acompañada por una modificación sustantiva de los contenidos flexibilizadores negociados en la década de 1990.

La principal diferencia con relación a aquellos años radica en la negociación dinámica de salarios. El "retorno" de la negociación de salarios responde a tres procesos, específicos y articulados, abiertos a partir de la devaluación del peso en enero de 2002. Por un lado, dos condiciones objetivas: la profunda caída del salario real posterior a la modificación del tipo de cambio en virtud del proceso inflacionario posterior, acelerado a partir de 2007, y la significativa reducción de la tasa de desempleo abierto entre 2003 y 2007 y su mantenimiento por debajo del $10 \%$ en los años siguientes. Por otro lado, estas condiciones objetivas permitieron al kirchnerismo canalizar e institucionalizar la impugnación al neoliberalismo expresada en las movilizaciones sociales de diciembre de 2001. En este proceso, los trabajadores ocupados y sus sindicatos, que mantuvieron una estructura no competitiva y centralizada, pasaron a ser los principales protagonistas del conflicto laboral centrado en las demandas para conquistar mejoras en el salario real y en la distribución del ingreso. Como señalamos al comienzo, este proceso se caracteriza más por una recobrada centralidad de la lucha sindical que por un "retorno" de los sindicatos a la escena política y laboral, de la cual nunca estuvieron ausentes.

Ahora bien, las características de la negociación salarial no dejan de poner de manifiesto las dificultades que enfrentan los trabajadores en la lucha 
económica. Ello se aprecia a partir del estudio de la composición de los salarios y de las características de los aumentos negociados en paritarias. En este sentido —así como la recuperación del salario real fue posible a partir de la significativa reducción del desempleo-, es preciso señalar que la magnitud del empleo no registrado constituye una condición clave para comprender los bajos niveles salariales en términos históricos y las condiciones de la recuperación salarial reciente.

La centralidad y las características de la negociación salarial y las continuidades en materia de flexibilización laboral plantean la importancia de indagar cómo interviene la estrategia y orientación política de la dirigencia sindical en la definición de los contenidos negociados y de qué modo delimita el horizonte de reivindicaciones. Particularmente, cabe interrogarnos cómo se relacionan dichos contenidos con la estrategia del sindicalismo tradicional que recobró protagonismo en la disputa económico-corporativa en los años recientes. A su vez, considerando la conformación de las expresiones del sindicalismo de base, resulta necesario analizar cómo inciden las divisiones intrasindicales en la negociación colectiva. Por último, resulta significativo pensar las características y contenidos de la negociación colectiva en relación con disputas intersindicales. Estas problemáticas quedan planteadas para futuras investigaciones.

\section{Referencias}

Amar, Anahí, Federico Pastrana, y Soledad Villafañe, 2010, "Costos laborales y competitividad en la Argentina post convertibilidad", ponencia presentada en el $2^{\circ}$ Congreso Anual de AEDA, septiembre, Buenos Aires.

Atzeni, Mauricio, y Pablo Ghigliani, 2008, "Nature and Limits of Trade Unions’ Mobilizations in Contemporary Argentina”, en Labour Again Publications, Amsterdam, International Institute of Social History.

Battistini, Osvaldo, 2000, La negociación colectiva y la estructura sindical en Argentina (19881998), tesis de Maestría en Ciencias Sociales del Trabajo, Centro de Estudios Avanzados, Universidad de Buenos Aires.

Boletin de Estadísticas Laborales, varios años, Ministerio de Trabajo, Empleo y Seguridad Social de la Nación, Argentina.

Castillo, Cristian, 2007, "Un recorrido por la lucha de clases en la Argentina reciente (19932006)", ponencia presentada en las Ix Jornadas Interescuelas / Departamento de Historia, 19-22 de septiembre, Argentina, S. M. de Tucumán. 
Cotarelo, María Celia, 2007, "Movimiento sindical en Argentina 2004-2007: ¿Anarquía sindical?”, ponencia presentada en las XI Jornadas Interescuelas / Departamento de Historia, Universidad Nacional de Tucumán, 19-21 de septiembre, S. M. de Tucumán, Argentina.

Encuesta Permanente de Hogares, varios años, Instituto Nacional de Estadísticas y Censos, Argentina.

Eskenazi, Matías Ezequiel, 2011, “Acumulación de capital y conflictividad laboral en argentina 2002-2009: Ejercicio de periodización e hipótesis de trabajo”, ponencia presentada en el xxviII Congreso aLAS, Recife, Brasil.

Etchemendy, Sebastián, y Ruth Collier, 2007, "Down but Not Out: Union Resurgence and Segmented Neocorporatism in Argentina (2003-2007)", Politics \& Society, vol. 35, núm. 3, pp. 363-401.

Fernández, Ana L., y Mariana González, 2012, "La desigualdad en los ingresos laborales. Su evolución en la posconvertibilidad”, Apuntes para el Cambio, núm. 3, Buenos Aires, pp. 18-32, [en línea], disponible en <http://www.apuntesparaelcambio.com.ar/apc_n3.pdf>, consultado el 1 de febrero de 2013.

Guevara, Sebastián, 2012, "Reactivación de la movilización obrera en la industria terminal automotriz (2004-2011). Recuperación parcial del salario con persistencia en la flexibilización laboral", Trabajo y Sociedad, núm. 19, pp. 515-539.

Información Económica al Día, varios años, Ministerio de Economía y Finanzas Públicas de la Nación, Argentina.

Marshall, Adriana, 2006, "Afiliación sindical e instituciones del trabajo: análisis comparativo", Estudios del Trabajo, núm. 32, pp. 29-54.

Marshall, Adriana, y Laura Perelman, 2008, "Estrategias sindicales de afiliación en la Argentina", Desarrollo Económico, vol. 48, núm. 189, pp. 3-30.

Marticorena, Clara, 2013, "Relaciones laborales y condiciones de trabajo en la industria manufacturera durante la postconvertibilidad en Argentina”, en J. Grigera (comp.), La Argentina después de la convertibilidad (2002-2011), Buenos Aires, Imago Mundi, pp. 135-162.

Marticorena, Clara, 2012, "Un análisis acerca de las categorías socioprofesionales en la negociación colectiva y sus transformaciones en las últimas décadas”, Trabajo y Sociedad, núm. 18, vol. Xvi, pp. 217-234. 
Marticorena, Clara, 2010, "Contenidos de la negociación colectiva durante la década de 1990 y la posconvertibilidad en actividades seleccionadas de la industria manufacturera”, Estudios del Trabajo, núm. 39/40, pp. 59-87.

Medina, Jorge, Marcelo Delfini, y Ana Drolas, 2012, "Las relaciones laborales en la postconvertibilidad. Continuidades y rupturas en la negociación colectiva”, ponencia presentada en las VII Jornadas de Sociología de la Universidad de General Sarmiento (Ungs), Buenos Aires.

Meyer, Laura, y Gutiérrez Gastón, 2005, "Las luchas obreras y los avances en la subjetividad”, en Lucha de clases, núm. 5, disponible en <http://www.ips.org.ar/wp-content/uploads/2011/03/ Las-luchas-obreras-y-los-avances-en-la-subjetividad.pdfs.

Michelena, Gabriel, 2009, "La evolución de la tasa de ganancia en la Argentina (1960-2007): caída y recuperación”, Revista de Ciencias Sociales Realidad Económica, núm. 248, pp. 83-106.

Novick, Marta, y David Trajtemberg, 2000, La negociación colectiva en el periodo 1991-1999, Documento de Trabajo núm. 19, Argentina, Secretaría de Trabajo, Coordinación de Investigaciones y Análisis Laborales, MTEss.

Observatorio del Derecho Social, s/f, Modelo sindical y aportes obligatorios. Un análisis de las cláusulas de solidaridad y de las contribuciones patronales incorporadas en los convenios colectivos de trabajo en Argentina (2002-2006), Buenos Aires, Central de Trabajadores Argentinos.

Observatorio del Derecho Social, 2008, La negociación colectiva 2003-2007. Un estudio comparativo con el periodo 1991-1999, en particular sobre la regulación de jornada y organización del trabajo, Buenos Aires, Central de Trabajadores Argentinos.

Palomino, Héctor, 2008, "La instalación de un nuevo régimen de empleo en Argentina: de la precarización a la regulación”, Revista Latinoamericana de Estudios del Trabajo, ańo 13, núm. 19, pp. 121-144.

Palomino, Héctor, y David Trajtemberg, 2006, "Una nueva dinámica de las relaciones laborales y la negociación colectiva en la Argentina”, Revista de Trabajo, año 2, núm. 3, pp. 47-68.

Piva, Adrián, 2006, "El desacople entre los ciclos del conflicto obrero y la acción de las cúpulas sindicales en Argentina (1989-2001)”, Estudios del Trabajo, núm. 31, pp. 23-52.

Senén González, Cecilia, y Julieta Haidar, 2010, "Revitalización sindical en perspectiva comparada. Un aporte al análisis sectorial en Argentina”, en A. Fernández, y Cecilia Senén González (comps.), Estado, instituciones laborales y acción sindical en paises del MERCosur frente al contexto de la crisis mundial, Buenos Aires, Prometeo, pp. 231-261. 
Senén González, Cecilia, David Trajtemberg, y Bárbara Medwid, 2010a, "Tendencias actuales de la afiliación sindical en Argentina: evidencias de una encuesta a empresas", Relations Industrielles / Industrial Relations, vol. 65, núm. 1, pp. 30-51.

Senén González, Cecilia, David Trajtemberg y Bárbara Medwid, 2010b, "Los determinantes de la negociación colectiva en la argentina. Debates teóricos y evidencias empíricas”, Trabajo, ocupación y empleo, Serie Estudios 9, Buenos Aires, MTESs, pp. 13-35.

Soul, Julia, 2011, "Políticas empresarias y estrategias sindicales en la industria siderúrgica. ¿Expresión de una nueva legalidad industrial?”, ponencia presentada en el 10 Congreso Nacional de Estudios del Trabajo, Buenos Aires, ASET.

Trajtemberg, David, Bárbara Medwid, y Cecilia Senén González, 2008, "La expansión de la afiliación sindical: Análisis del módulo de relaciones laborales de la EIL", Trabajo, ocupación y empleo, Serie Estudios 8, Buenos Aires, MTEss, pp. 13-34.

Trajtemberg, David, Fabián Berhó, Paula Attorressi, y Walter Lauphan, 2005, "Encuesta de Relaciones Laborales", ponencia presentada en el $7^{\circ}$ Congreso Nacional de Estudios del Trabajo, ASET, Buenos Aires.

Varela, Paula, 2013, "El sindicalismo de base en la Argentina postdevaluación. Hipótesis sobre sus alcances y potencialidades.”, en J. Grigera (comp.), La Argentina después de la convertibilidad (2002-2011), Buenos Aires, Imago Mundi, pp. 115-133.

Varela, Paula, 2010, "Entre la fragmentación de los trabajadores y los negocios propios (o sobre qué se sostiene la actual burocracia sindical)", Revista Nuevo Topo, núm. 7, Buenos Aires, pp. 75-89.

Recibido el 17 de julio de 2013. Aceptado el 27 de octubre de 2014. 